\title{
Performance of Low Smeared Density Sodium-cooled Fast Reactor Metal Fuel
}

D. L. Porter, H. J. M. Chichester, P. G. Medvedev, S. L. Hayes and M. C. Teague

Idaho National Laboratory

P. O. Box 1625, Idaho Falls, ID 83415-6188 U.S.A.

\section{Corresponding Author Contact Information:}

\section{Douglas L. Porter}

Fuel Performance and Design

Idaho National Laboratory

P.O. Box 1625

Idaho Falls, ID 83415-6188 U.S.A.

Phone: 1 (208) 533-7659

Fax: 1 (208) 533-7863

Email: Douglas.Porter@inl.gov

Submitted to Journal of Nuclear Materials

August 2011

This manuscript has not been published elsewhere and has not been submitted simultaneously for publication elsewhere. 


\begin{abstract}
An experiment was performed in the Experimental Breeder Rector-II (EBR-II) in the 1990s to show that metallic fast reactor fuel could be used in reactors with a single, once-through core. To prove the long duration, high burnup, high neutron exposure capability an experiment where the fuel pin was designed with a very large fission gas plenum and very low fuel smeared density (SD). The experiment, X496, operated to only 8.3 at. \% burnup because the EBR-II reactor was scheduled for shut-down at that time. Many of the examinations of the fuel pins only funded recently with the resurgence of reactor designs using very high-burnup fuel. The results showed that, despite the low smeared density of 59\% the fuel swelled radially to contact the cladding, fission gas release appeared to be slightly higher than demonstrated in conventional 75\%SD fuel tests and axial growth was about the same as 75\% SD fuel. There were axial positions in some of the fuel pins which showed evidence of fuel restructuring and an absence of fission products with low melting points and gaseous precursors ( $\mathrm{Cs}$ and $\mathrm{Rb}$ ). A model to investigate whether these areas may have overheated due to a loss of bond sodium indicates that it is a possible explanation for the fuel restructuring and something to be considered for fuel performance modeling of low SD fuel.
\end{abstract}




\section{Keywords}

Fast Reactor metallic fuel

Low smeared density nuclear fuel 


\section{Introduction}

In recent years there has been an interest in extended life driver fuel for a fast flux reactor, as a means for increased fuel efficiency, to potentially reduce waste volumes and to support core concepts where a single-use (once through) core is incorporated. Metal fuel concepts are being considered for this purpose. $[1,2,3]$. To facilitate high burnup potential without cladding failure, particular interest is to incorporate design features that would decrease potential fuel/cladding mechanical interaction (FCMI) by allowing space within the cladding for extended fuel swelling, enhanced gas release to an enlarged gas plenum and the reduction of fuel/cladding chemical interaction.

Experimental Breeder Reactor -II (EBR-II) experiment X496 was designed to show that fast reactor metal fuel could be used in a once-through reactor concept. The objective was to show that fuel could be designed to be used to very high burnup. To accomplish this it was envisioned that a low smeared density (much less than $75 \%$ ) and a large fission gas plenum would be the key design changes required to achieve very high burnup (> 30 at. \% heavy metal). A smeared density (SD) of 75\% provides for fission gas release sufficient to prevent fuel swelling from creating large stresses on the cladding [4], and reducing SD further allows for build-in of solid fission products to high burnup while not compromising the gas release effect.

A low swelling cladding would also be important to reach extended burnups so the ferritic-martensitic alloy HT9 was chosen. Ninety-three percent ${ }^{235} \mathrm{U}$ enriched uranium was chosen to be used in the U-10Zr (wt \%) fuel to achieve high burnup as quickly as possible. There had already been extensive irradiation testing of U-10Zr fuel in EBR-II and the Fast Flux Test Facility (FFTF) reactor [5] so the fuel behavior of standard $75 \%$ smeared density U-10Zr was well characterized.

The test began irradiation in early in 1993 (Run 163A) and removed in 1994 (after Run 170A) after only $\sim 8.3$ at.\% peak burnup. EBR-II was shut down after Run 170B. The fuels program scope was also changed so except for neutron radiography there was no remaining funding to perform any more examinations of the as-irradiated fuel. Recently there was renewed interest in designing long-life fuel so a subset of the fuel pins ( 8 of 37) were exhumed from underground silo storage and examined.

X496 is one of the few times sodium fast reactor (SFR) metal fuel with a low smeared density has been irradiated and examined. An early EBR-II test of Pu-bearing metal fuel (nominally U-15Pu-10Zr) tested fuel (13 pins) with smeared density of 73-75\%, but the remaining three pins had a SD of 66\%.[6] The pins were irradiated to $\sim 4.5$ at. $\%$ peak burnup. The fission gas release of the ten $\sim 74 \%$ SD pins measured was $60-63 \%$ while the $66 \%$ SD pin punctured for fission gas showed a $71 \%$ release.

Subsequently, EBR-II test X441was built to investigate the performance of metal fuel with varied designs. The $\mathrm{Zr}$ content, the smeared density and the plenum size were all varied to observe the effects. The smeared density was tested at 70,75 , and $85 \%$. Of most interest in this test was the higher smeared density to document any extra fuel/cladding mechanical interaction (FCMI) in the form of cladding strains.

Seventy-five percent smeared density was being used extensively for metallic driver fuel because it was shown theoretically that starting at $75 \%$ SD allowed gas bubble porosity to interconnect and the 
fission gas could be released to the gas plenum of the fuel pin.[4] The design of driver fuel for EBR-II was changed to incorporate a 75\% SD.[7] The validity of the assumption of gas release has been documented by extensive gas release measurements on irradiated fuel .[8,9] Also, the earlier versions of EBR-II driver fuel, those with $85 \%$ SD were limited to a low peak burnup of 1.7 at.\% because of cladding Breach. But these designs also had restraint to limit axial fuel growth. X441 would show whether a higher SD could be used if axial restraint was removed. Seventy percent SD pins were included in the X441 test to demonstrate the effect of lessening FCMI.

The results of post-irradiation examinations showed that the axial growth averaged $1.8 \%$ for the $75 \%$ SD U-19Pu-10Zr pins while the 70\% SD pins grew 2.6\%.[10] Note that the U-19Pu-10Zr swells axially less than U-10Zr fuel.[11] The cladding diameter strains were the same for 70 and $75 \%$ SD but the strains were much larger for the $85 \% \mathrm{SD}$ pins, $1.7 \% \Delta \mathrm{D} / \mathrm{D}$ compared to $0.3 \% \Delta \mathrm{D} / \mathrm{D}$ at $75 \% \mathrm{SD}$, but no pins breached. The test successfully showed that a higher smeared density fuel could be utilized to a relatively high peak burnup of $\sim 11$ at. $\%$. The controls at 70 and $75 \%$ SD contrasted the performance of the higher SD fuel. Although a higher smeared density fuel was never qualified for use, this test provided fuel performance data needed to validate fuel performance models.

X496 testing of lower smeared density was for another purpose. This was to be a driver fuel design feature for a reactor incorporating a once-through core. It was therefore very desirable to achieve a very high burnup with the fuel. At very high burnups, however, it was theorized that the cumulative deposition of solid fission products would cause additional fuel swelling, begin to close open porosity and cause higher fission gas retention.[12] This would in turn allow higher fuel/cladding mechanical interaction (FCMI) stresses to develop, potentially causing creep rupture of the cladding. Use of a very low SD may allow for enough additional porosity to absorb the effects of the accumulation of solid fission products. A smeared density of $\sim 60 \%$ was envisioned for the test. The fuel pin design utilized had a SD of $58.6 \%$.

\subsection{Axial Growth of Low SD Fuel}

Of particular interest in this test, where such a low SD was used, was the axial growth of the fuel. Standard 75\% SD U-10Zr fuel had shown an axial fuel growth of only 8-9\%.[11] When a 75\% SD fuel swells radially and contacts the cladding the radial and circumferential strains have each reached $\sim 16 \%$, yet the axial strains are not $16 \%$ at this point indicating a different restraint mechanism for axial vs radial growth. It has been hypothesized that the axial growth is restrained for the same reason that plastic axial strain in a balanced-biaxial (thin-walled) pressurized cylindrical tube is not observed. In such a tube the stress state in the walls shows no deviatoric component in the axial direction and therefore no plastic strains are created as the pressure is increased beyond the yield stress.

The fuel slug acts in the same manner as the tube in that the radial temperature distribution creates a soft center which is swelling due to fission gas generation (like the gas in the pressurized tube), and the colder fuel near the cladding is much stronger (acting like the walls of the pressurized tube), restraining the axial growth until the fuel has swelled out to the cladding. Of course this isn't a perfect balanced biaxial pressurized tube so there is some axial growth. An example which is nearer to theory was an experiment where the fuel slug was cast into a thin-walled $\mathrm{Zr}$ mold; the entire slug/mold combination was clad and irradiated. At 2 at.\% BU the fuel had swelled axially only 1.3\%[13] the standard cast fuel 
irradiated with these pins swelled 8.0\%, consistent with the results of other tests.[11] In this case the strong $\mathrm{Zr}$ mold restrained the fuel axial growth.

The question was asked whether fuel with a SD much lower than $75 \%$ would experience more growth in the axial dimension, or perhaps slump from lack of axial support afforded by the cladding. X496 data could be used to answer these questions as well.

\subsection{Gas Release in Low SD Fuel}

Fission gas release from low SD fuel was also unknown. There is a great deal of information concerning gas release from 75\% SD fuel. The gas release behavior from 75\% SD fuel is consistent with modeling of the formation of 'open', or connected, porosity in the fuel as fission gas bubbles grew and connected, forming pathways for fission gas to be released. This effect can be compromised at high burnup when solid fission products have deposited in the fuel and begin to close off the open porosity. Fission gas retention would increase and the fuel could apply more stress to the cladding. If a lower smeared density fuel were utilized, and if the fuel continued to swell to the cladding walls, then there would be an even larger fraction of 'open' porosity. As fuel burnup is allowed to continue to high values, such as 25 or $30 \%$, the excess open porosity would be able to accumulate more solid fission products without increasing fission gas retention.

\section{X496 Design and Irradiation Conditions}

The X496 irradiation test consisted of 37 fuel pins, all with U-10wt\% Zr fuel. Design parameters are shown in Table 1. Note that the plenum-to-fuel volume ratio $(\mathrm{P} / \mathrm{F})$ was $\sim 3$ while most other experiments and standard driver fuel had a $\mathrm{P} / \mathrm{F}$ of $1-1.5$. The upper reflector in the assembly was shortened to accommodate the extra plenum length.

X496 was loaded into the EBR-II core early in 1993 (Run 163A) and removed in 1994 (after Run 170A); EBR-II was shut down after Run 170B. The burnup goal for the X496 test was 20 at.\%, but the program was cancelled, and EBR-II was shut down just after the experiment reached 8.3 at.\%. Individual pin thermal conditions are shown subsequently in this report.

\section{Table 1. Design parameters for X496 pins and assembly.}

\section{Characterization of Irradiated Pins}

There were eight X496 fuel pins exhumed from used fuel storage for examination in 2011. Figure 1 is a loading diagram for X496 and the eight pins are highlighted with shading. The eight pins exhumed were further examined by precision gamma scanning and axial profilometry designed to measure the pin diameter as a function of axial position. Then two of the pins were LASER punctured to sample the plenum gas and measure the amount of released fission gas. Metallography was then performed. Profilometry showed little or no diameter change at this fuel burnup. The neutron radiography and gas release information will be presented here as these exams provide information pertinent to the performance of low smeared density fuel. 
Figure 1. Loading of the X496 assembly with pin identification numbers. The shaded pins are those receiving the full scope of examinations.

\subsection{Axial Fuel Growth}

All 37 fuel pins from the X496 experiment had previously been neutron radiographed. This allowed a measurement of the axial fuel growth in most of the pins in the assembly. The axial fuel growth can be measured directly by measuring the fuel column length on the radiograph and comparing that length to the original measured length of the fuel slug. A second method to measure the length of the fuel column is to use precision gamma scanning to trace the signal of an active isotope (fission product or daughter of) which is tightly bound to the fuel matrix, such as ${ }^{95} \mathrm{Nb}$ and ${ }^{95} \mathrm{Zr}$ or ${ }^{103} \mathrm{Ru}$. Unfortunately only eight pins were available for gamma scanning, and all of these pins had completed irradiation more than 19 years ago. The isotopes of interest had decayed to a degree where the radioactivity of these isotopes was not sufficient to get an accurate measurement of fuel column length.

Either of these methods involves subjective judgment performing the measurements.. The radiographs often show a gradient in the fuel density at the top of the fuel. This gradient is most visible in fuel that was irradiated at fairly low fuel temperatures $\left(<650^{\circ} \mathrm{C}\right)$. One set of neutron radiographic images of the tops and bottoms of X496 fuel columns is shown in Figure 2. The density gradient at the top of the fuel column is clear in pins CL07 and CL18. It also shows why choosing the location of the top of the fuel column is subjective. Note also that other material (above the fuel column) also causes contrast in the image; chemical analysis has shown that this is not heavy metal species, but instead fission products. In this study the place where the low density 'dome' in CL07 begins is the elevation where the fuel column length was declared as shown by the horizontal line at the top of CL07 in Figure 2.

Note also the lift-off of the fuel column in pin CL18 (the fuel column is not seated on the lower end plug insert). This phenomenon has been observed before and attributed to strains created by cyclic phase transformations of the U-based fuel as the reactor is started up and shut down, and assisted by thermal expansions and contractions and/or fission gas accumulations creating a differential pressure. The lift-off is followed by axial fuel growth downwards to fill in the cavity left by the fuel column lift-off. It is possible that many of, or all of the pins exhibit the phenomenon to some extent but the lift-off is no longer visible after the fuel has swelled into the void. Lift-off was visible in the radiographs of five of the thirtyseven pins. Separation of the fuel column was also observed, including small portions of the upper part of the fuel column sometimes (in four pins) being found well above the bulk of the fuel column. This has not been observed in other experiments. If it was not possible to make a simple and obvious summation of segments the radiographic interpretation of the axial growth was not used.

Figure 2. Thermal neutron radiography (Dy foil activation) showing the top and bottom areas of six X496 fuel pins. The short line drawn at the top of the CLO7 fuel column indicates where the top of the fuel column was chosen, subjectively.

Table 2 shows the measured axial growth of the thirty-seven pins from X496 as measured by analyzing the thermal neutron radiographs. The blank fields for axial growth reflect that two pins were not radiographed and that fuel column separation negated an accurate measurement of others. The axial growth varies from $7.1 \%$ to $11.0 \%$. Pins were identified as having been located in certain regions of the fuel bundle while being irradiated. These locations were outer row or inner row positions (there are four 
hexagonally shaped rows in a 37-pin bundle). The outer row pins have fewer nearest neighbors and therefore usually operate at lower temperatures.

The temperatures were calculated for beginning of life conditions using COBRA-WC and THT-B codes and using EBR-II Run 150B data. Conservatism was built in to the beginning-of-life calculations by assuming a Row 1 position and $6.5 \mathrm{~kg} / \mathrm{s}$ sodium flow based upon a standard assembly design. As-run information (Row 3) indicated the flows were as high as $6.6 \mathrm{~kg} / \mathrm{s}$ of sodium because the upper reflector was shortened to allow for the larger gas plenums. Also, linear pin powers were as much about three percent less than used as a constant $56.4 \mathrm{KW} / \mathrm{m}$, average, in the analysis. Therefore these calculations are only slightly conservative (higher operating temperatures), $\sim 5^{\circ} \mathrm{C}$ in cladding temperature and $\sim 13{ }^{\circ} \mathrm{C}$ in fuel centerline. This analysis also assumed that the fuel hadn't swollen so the fuel centerline temperatures are low, before fuel swelling.

An analysis performed subsequent to this using the SAFE Code[14] to detail fuel centerline temperatures as the fuel swelled and logged with sodium. The results indicated that there may have been periods during the irradiation where fuel temperatures were $\sim 50{ }^{\circ} \mathrm{C}$ higher compared to the numbers inTable 2, early in life just as the fuel swelled out to the cladding. However, the BOL temperatures were presented here because the axial growth likely occurred early in life, before fuel/cladding contact.

Table 2 - Axial growth of fuel in X496 fuel pins as measured by analyzing neutron radiographs compared to peak thermal conditions.

The information in Table 2 shows the following:

1. The overall average axial growth was $8.6 \%$.

a. The average of pins located in corner positions was $8.0 \%$.

b. The average of pins located in edge positions was $8.5 \%$

c. The average of pins located in the central bundle was $9.0 \%$.

The values listed above and the standard deviations for each are depicted in below in Figure 3. While there was a trend for the average growth to be larger for the pins operating hotter in the central bundle, the error shows that statistically one cannot come to this conclusion.

Figure 3. Graphical depiction of range and error associated with axial fuel growth measurements, showing no definitive correlation with pin position in the assembly bundle.

The beginning of life operating temperatures show the fuel centerline $\mathrm{T}$ of the central bundle pins operating about $10{ }^{\circ} \mathrm{C}$ higher than the edge or corner position pins and the peak cladding temperature about $20^{\circ} \mathrm{C}$ higher. It is relatively common to see fuel operating at higher temperatures swelling less; the opposite seems to the case here, but perhaps not significantly. The unusual structure of the fuel in places and lift-off may have influenced the data more than operating temperature. 


\subsection{Fission Gas Release}

Two pins were punctured to obtain fission gas volume and pressure in the gas plenum. The total gas production was calculated, allowing the gas release percentage to be calculated. The results are shown in Figure 4. The data suggest that the gas release in X496 fuel pins was higher than the pins with $75 \%$ SD, much as had be shown in 1969 for U-Pu-Zr fuel [6], however both data sets are statistically limited. Since the radiography indicates that the fuel has swollen out the cladding over most of the length of the fuel column, this is to be expected because it indicates there is a larger fraction of open porosity distributed over the entire internal cross-section of the cladding.

Figure 4. Comparison of axial fuel growth of X496 fuel columns compared with other EBR-II experiments using $75 \%$ smeared density fuel (base data taken from reference 7).

\subsection{Anomalous Structural Features}

The post-irradiation exams thus far have shown that the fuel performed very similarly to that of fuel with the higher $75 \%$ smeared density. In some cases the neutron radiographs indicated features that have not been observed previously in fast reactor metal fueled experiments. One such feature appeared in four of the thirty-seven pins where small lengths of fuel column $(2-3 \mathrm{~cm}$ long) were displaced into the gas plenum region. Note that segments this long have masses of $\sim 6 \mathrm{~g}$ so even a small differential pressure can move the segment if they were gas tight and frictionless.

Another unusual feature is shown in Figure 5 where the fuel column shows a neutron radiography contrast that is non-uniform. These non-uniform regions have lower contrast indicating less fuel. The region is particularly extended in the CL20 radiograph, extending from $12 \mathrm{~cm}$ to $23 \mathrm{~cm}$ elevation from the bottom of the fuel pin. This length represents the entire image shown in Figure 5 for CL20. Precision gamma scanning showed that the areas had a much lower Cs-137 activity than did axial regions adjacent to them. Figure 6 shows the Cs-137 gamma scans of two of the X496 pins, CL18 and CL20. The peak at the top of the fuel (bottom of the gas plenum) is typical of other sodium bonded fuel experiments in EBRII, where Cs collects in the bonds sodium atop the fuel column. CL18 demonstrates the typical profile for Cs. The sudden drop in Cs-137 activity in CL-20 was not expected and corresponds to the axial positon of the anomalous structure shown in Figure 5.

In corroboration of the gamma scan results chemical analysis of fuel in one of these regions showed that there was significantly less $\mathrm{Cs}$ and $\mathrm{Rb}$ than in other places in the fuel column. While these elements both have low melting temperatures they also are born as daughters of gaseous fission products, Xe and $\mathrm{Kr}$, respectively. Each could have provided the opportunity for redistribution of the species.

These characteristics may provide clues as to the mechanisms creating the fuel structure. One such explanation may be that because of the higher percentage of porosity in this low smeared density fuel the bond sodium which often infiltrates (logs) open porosity in the fuel was more easily expelled from the area by fission gas release. Since Cs is often found with the Na this would explain the lack of Cs in these areas. A lack of logged sodium also decreases the thermal conductivity of the fuel. The fuel center would then operate at higher temperature, perhaps high enough for the porous fuel structure to collapse. 
Note also that the two pins in Figure 5 were located in the assembly bundle as the centermost pin and one in the six-pin row next to it. As such, they would have been two of the highest temperature pins in the assembly.

Figure 5. Enlargement and enhanced (brightness increased) fuel column regions of CL20 and CL36 showing areas of unusual structure. These regions of the pin shown in the radiographs represent elevations of $12-23 \mathrm{~cm}(\mathrm{CL20})$ and $28-31.5 \mathrm{~cm}$ (CL36) from the bottom of the pin.

\section{Figure 6. Cesium-137 gamma scans of pins CL18 and CL20}

To investigate the possibility that the high fraction of open and non-logged porosity may have temperatures at fuel centerline high enough for the fuel structure to collapse we perform the following calculation.

Fuel swelling is a sum of the solid and fission gas swelling:

$$
\left(\frac{\Delta V}{V_{0}}\right)_{\operatorname{tosal}}=\left(\frac{\Delta V}{V_{0}}\right)_{g}+\left(\frac{\Delta V}{V_{0}}\right)_{s}
$$

Swelling due to solid fission products is $1.5 \%$ per $1 \%$ burnup [15]:

$$
\left(\frac{\Delta V}{V_{0}}\right)_{s}=0.015 \times 8.3=0.12
$$

Therefore, swelling due to fission gas:

$$
\left(\frac{\Delta V}{V_{0}}\right)_{g}=\left(\frac{\Delta V}{V_{0}}\right)_{\text {total }}-\left(\frac{\Delta V}{V_{0}}\right)_{s}=0.88-0.12=0.76
$$

Fuel porosity is equal to:

$$
p=\frac{\left(\frac{\Delta V}{V_{0}}\right)_{g}}{\left(\frac{\Delta V}{V_{0}}\right)_{g}+1}=\frac{0.76}{0.76+1}=0.43
$$

Now assume the porosity is very open (connected), enough so that bond sodium, that can infiltrate the open pores, is expelled. It is sometimes assumed, guided by some measurements, that $\sim 50 \%$ of the open pores are infiltrated, or 'logged' by bond sodium. This assumption is usually used for thermal analysis of the fuel. The 'logged' sodium increases the thermal conductivity and keeps the fuel centers cooler. Assuming the absence of $\mathrm{Cs}$ and $\mathrm{Rb}$ indicates the potential absence of $\mathrm{Na}$, the fuel temperature would increase. 
The analytical solution for the fuel centerline temperature is as follows:

$T_{f c}=T_{c o}-\frac{q^{\prime}}{2 \pi k_{c}} \ln \left(\frac{R_{c i}}{R_{c o}}\right)-\frac{q^{\prime}}{2 \pi k_{N a}} \ln \left(\frac{R_{f}}{R_{a i}}\right)+\frac{q^{\prime}}{4 \pi k_{f}}$

Where

$\mathrm{T}_{\mathrm{fc}}$-fuel centerline temperature,

$\mathrm{T}_{\mathrm{co}}$-cladding outer temperature,

q'-linear heat generation rate,

$\mathrm{k}_{\mathrm{c}}$ - thermal conductivity of the cladding $0.26 \mathrm{~W} / \mathrm{m} \mathrm{K}$,

$\mathrm{k}_{\mathrm{f}}$-thermal conductivity of the fuel,

$\mathrm{k}_{\mathrm{Na}}$-thermal conductivity of the bond,

$\mathrm{R}_{\mathrm{co}}$-cladding inner diameter,

$\mathrm{R}_{\mathrm{ci}}$-cladding outer diameter,

$\mathrm{R}_{\mathrm{f}}$-fuel radius.

Fuel thermal conductivity calculated using methodology described by Karahan [16]:

$k_{f}=P_{o}(1-P)^{1.5} k_{0}$

Where

$\mathrm{k}_{0}$-fabricated fuel thermal conductivity [16]:

$$
k_{0}=a+b T+c T^{2}, \mathrm{~W} / \mathrm{m} \mathrm{K}
$$

$a=17.5 \frac{1-2.23 W_{z}}{1+1.61 W_{z}}$

$b=1.54 \times 10^{-2} \frac{1+0.061 W_{z}}{1+1.61 W_{z}}$

$c=9.38 \times 10^{-6}$

$\mathrm{W}_{\mathrm{Z}}$-weight fraction of zirconium in the fuel,

$\mathrm{P}_{\mathrm{c}}$-porosity correction due to $\mathrm{Na}$ logging [16]: 
$P_{\sigma}=1-\frac{3 P_{N a}}{1-P} \times \frac{1-\frac{k_{N a}}{k_{0}}}{1.163+1.837 \frac{k_{N a}}{k_{0}}}$

Where $\mathrm{P}_{\mathrm{Na}}$-fraction of the porosity which is filled with sodium.

Thermal conductivity of the sodium [16] is calculated as follows:

$k_{N a}=93-0.0581 T+1.173 \times 10^{-5} T^{2}(\mathrm{~W} / \mathrm{m} / \mathrm{K})$

Where $\mathrm{T}$ is the sodium temperature in degrees Celsius.

Using equations presented above, the fuel temperature for linear heat generation rate of $63.3 \mathrm{~kW} / \mathrm{m}$ (peak) and cladding outer temperature of $488^{\circ} \mathrm{C}$ was calculated. Fuel temperature is shown in Error!

Reference source not found. as a function of fuel porosity with $50 \%\left(\mathrm{P}_{\mathrm{Na}}\right)$ sodium logging, and without sodium logging. It is assumed that sodium logging begins when porosity exceeds 0.25 . As evident from Figure 7, expulsion of logged sodium from the fuel with $43 \%$ porosity operating at the power of $63.3 \mathrm{~kW} / \mathrm{m}$ will result in a fuel temperature increase of approximately $150^{\circ} \mathrm{C}$. This may then exceed the $\mathrm{Na}$ boiling temperature of $883{ }^{\circ} \mathrm{C}$. Note that the linear pin power is the maximum expected for the maximum pin the bundle at beginning of life, so the fuel temperatures are the maximum to be expected.

\section{Figure 7. Fuel temperature as a function of fuel porosity with $50 \%$ sodium logging and without sodium logging. Dashed vertical line corresponds to $43 \%$ porosity.}

These centerline temperatures $\left(\sim 950^{\circ} \mathrm{C}\right)$ are untypically high for metal fast reactor fuels but it is not obvious that they would be high enough to cause collapse of the swollen fuel structure. The melting (solidus) temperature of $\mathrm{U}-10 \mathrm{Zr}$ is $1250^{\circ} \mathrm{C}$, so the centerline at beginning of life power is operating $300 \mathrm{C}$ below and 0.80 of the melting temperature, enough to significantly increase the creep rate of the fuel. However, there is not enough evidence to positively identify this mechanism as potentially creating the fuel features.

\section{Summary/Conclusions}

The previously irradiated (1993-1994) sodium-bonded metallic fast reactor fuel experiment, X496, was examined to characterize the performance of low smeared density fuel. The fuel had a smeared density of $58.6 \%$ compared to the usual $75 \%$. Axial fuel growth and fuel structure were characterized using neutron radiography and the gas plenums of several pins were punctured to measure fission gas release. The overall performance of the fuel was found to be very similar to $75 \%$ SD pins, but unique features were observed in some of the fuel columns where the fuel had a non-uniform structure. Also, and perhaps as expected, the gas release was higher than is usual for a 75\%SD pin, although this is a statistically limited data set (2 pins). The non-uniform areas had significantly reduced levels of $\mathrm{Cs}$ and $\mathrm{Rb}$ fission products, indicating that $\mathrm{Na}$ also may have been expelled from these regions. This would have created a fuel centerline temperature increase of $\sim 150^{\circ} \mathrm{C}$. This may have been enough to cause the 
change in fuel structure but more testing and analysis may be required to illustrate what operating conditions are required to create these non-uniform structures. This may be important to the future use of these low smeared density fuels.

\section{Acknowledgements}

This submitted manuscript was authored by a contractor of the U.S. Government under DOE Contract No. DE-AC07-05ID14517. Accordingly, the U.S. Government retains and the publisher, by accepting the article for publication, acknowledges that the U.S. Government retains a nonexclusive, paid-up, irrevocable, world-wide license to publish or reproduce the published form of this manuscript, or allow others to do so, for U.S. Government purposes.

The authors would like to thank all of those who provided post-irradiation examination data for this experiment, including Glen Papaioannou and all of the NRAD crew; Dave Sell, Scott White, and Dawnette Hunter; metallographers Brian Frickey and Cad Christensen; Paul Lind and Katelyn Wachs, all of the Hot Fuel Examination Facility; Mike Rodriquez, Jeff Giglio, and especially Dan Cummings of the Analytical Laboratory; not to mention all the others from those facilities and the Radioactive Scrap and Waste Facility (RSWF) who helped to retrieve the pins from silo storage.

\section{U. S. Department of Energy Disclaimer}

This information was prepared as an account of work sponsored by an agency of the U.S. Government. Neither the U.S. Government nor any agency thereof, nor any of their employees, makes any warranty, express or implied, or assumes any legal liability or responsibility for the accuracy, completeness, or usefulness of any information, apparatus, product, or process disclosed, or represents that its use would not infringe privately owned rights. References herein to any specific commercial product, process, or service by trade name, trademark, manufacturer, or otherwise, does not necessarily constitute or imply its endorsement, recommendation, or favoring by the U.S. Government or any agency thereof. The views and opinions of authors expressed herein do not necessarily state or reflect those of the U.S. Government or any agency thereof

\section{REFERENCES}

[1] Wright, A. E., S. L. Hayes, T. H. Bauer, H. J. Chichester, G. L. Hofman, J. R. Kennedy, T. K. Kim, Y. S. Kim, R. D. Mariani, W. D. Pointer, A. M. Yacout and D. Yun, Trans. Am. Nucl. Soc., vol.106, (2012) pp.1102.

[2] Chichester, H. J. M., R. D. Mariani, S. L. Hayes, A. E. Wright, Y. S. Kim, J. R. Kennedy, A. M. Yacout and G. L. Hofman., Trans. Am. Nucl. Soc., vol.106, (2012), pp.1349.

[3]Ohta, H., T. Ogata and T. Obara., Nuclear Technology, vol.187 (2014). pp.198.

[4] .Barnes, R.S., Journal of Nuclear Materials, v. 11 (1964) p. 135-148

[5] Crawford, D. C., D. L. Porter and S. L. Hayes, Journal of Nuclear Materials, v.371 (2007) p. 202-231. 
[6] Murphy, W. F., W. N. Beck, F. L. Brown, B. J. Koprowski and L. A. Neimark, Argonne National Laboratory Report, ANL-7602,1969.

[7] Hofman, G.L., Nuclear Technology, v.47 (1980) p. 7-22.

[8] Beck, W. N. and R. J. Fousek, Transactions of the American Nuclear Society 9 (2), 415 (1966).

[9] Pahl, R. G., R. S. Wisner, M. C. Billone, and G. L. Hofman, (1990), Proceedings of the International Fast Reactor Safety Meeting IV, 12-16 August, 1990 Snowbird, Utah, v. 4, pp. 129-138.

[10] Tsai, H., Cohen, A. B., Billone, M. C. and Neimark, L. A., Proceedings of the $3^{\text {rd }}$ International Conference on Nuclear Engineering (ICONE-3), Kyoto, Japan, April 23-27, 1995.

[11] Hofman, G. L., R. G. Pahl, C. E. Lahm, and D. L. Porter, (March 1990), Metallurgical Transactions, 21A, p 517-520.

[12] Hofman, G. L., L. C. Walters, and T. A. Bauer, (1997), Progress in Nuclear Energy, Vol. 31, No. 1, pp. 83-110.

[13] Crawford, D. C., C.E. Lahm, H. Tsai and R. G. Pahl, Journal of Nuclear Materials, v.204 (1993) p.157164.

[14] Hayes, S. L, ANL-IFR-221 (1993).

[15] Ogata, Takanari and Yokoo Takeshi, Nuclear Technology, v.128, Oct.1999, p.113-123.

[16] Karahan A., PhD Dissertation, Massachusetts Institute of Technology (2009). 


\section{LIST of FIGURES}

Figure 1. Loading of the X496 assembly with pin identification numbers. The shaded pins are those receiving the full scope of examinations.

Figure 2. Thermal neutron radiography (Dy foil activation) showing the top and bottom areas of six X496 fuel pins. The short line drawn at the top of the CL07 fuel column indicates where the top of the fuel column was chosen, subjectively.

Figure 3. Graphical depiction of range and error associated with axial fuel growth measurements, showing no definitive correlation with pin position in the assembly bundle.

Figure 4. Comparison of axial fuel growth of X496 fuel columns compared with other EBR-II experiments using $75 \%$ smeared density fuel (base data taken from reference 7 )

Figure 5. Enlargement and enhanced (brightness increased) fuel column regions of CL20 and CL36

showing areas of unusual structure. Note the non-uniform density with voided regions. 10

Figure 6. Cesium-137 gamma scans of pins CL18 and CL20 10

Figure 7. Fuel temperature as a function of fuel porosity with $50 \%$ sodium logging and without sodium logging. Dashed vertical line corresponds to $43 \%$ porosity. 
FIGURES

FIGURE 1

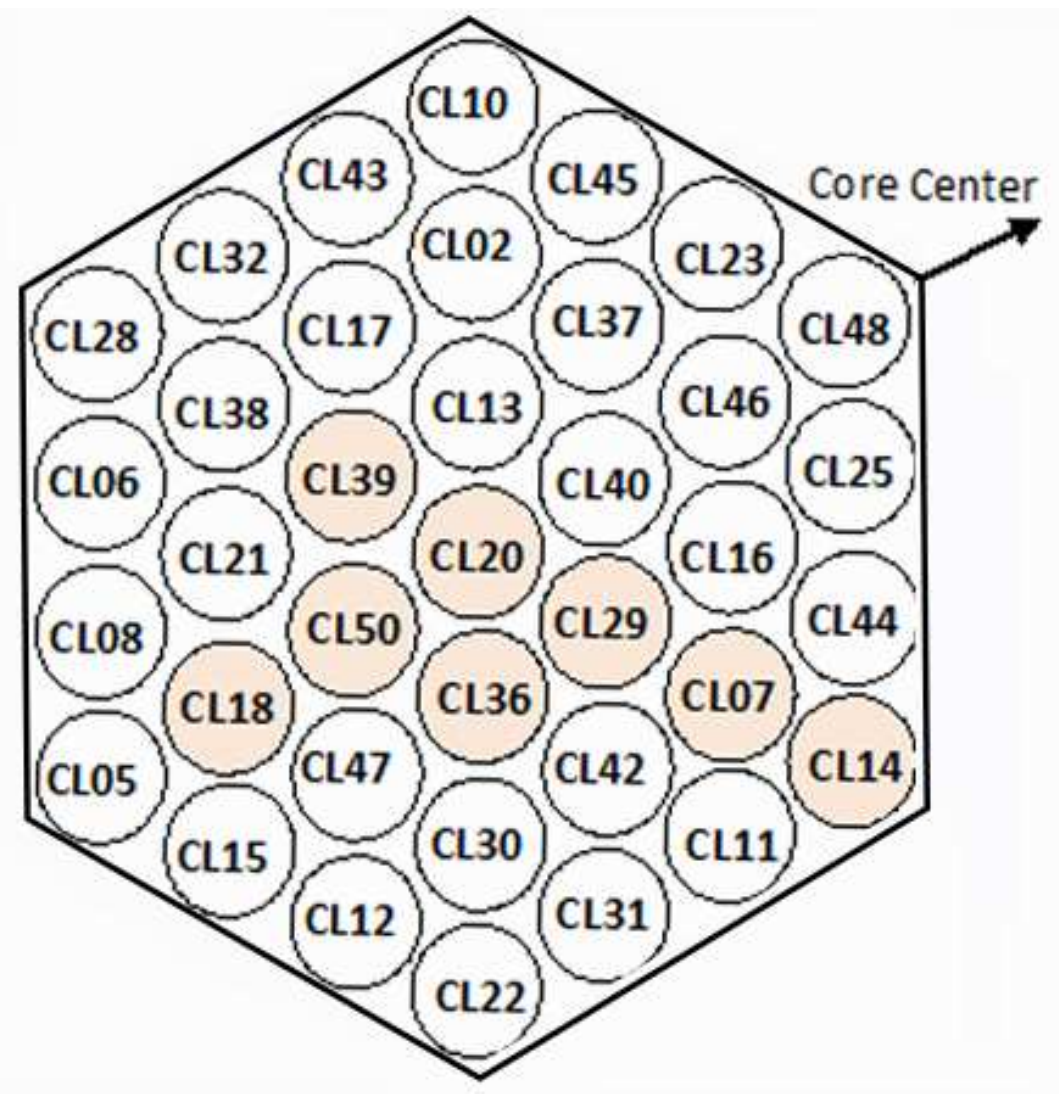




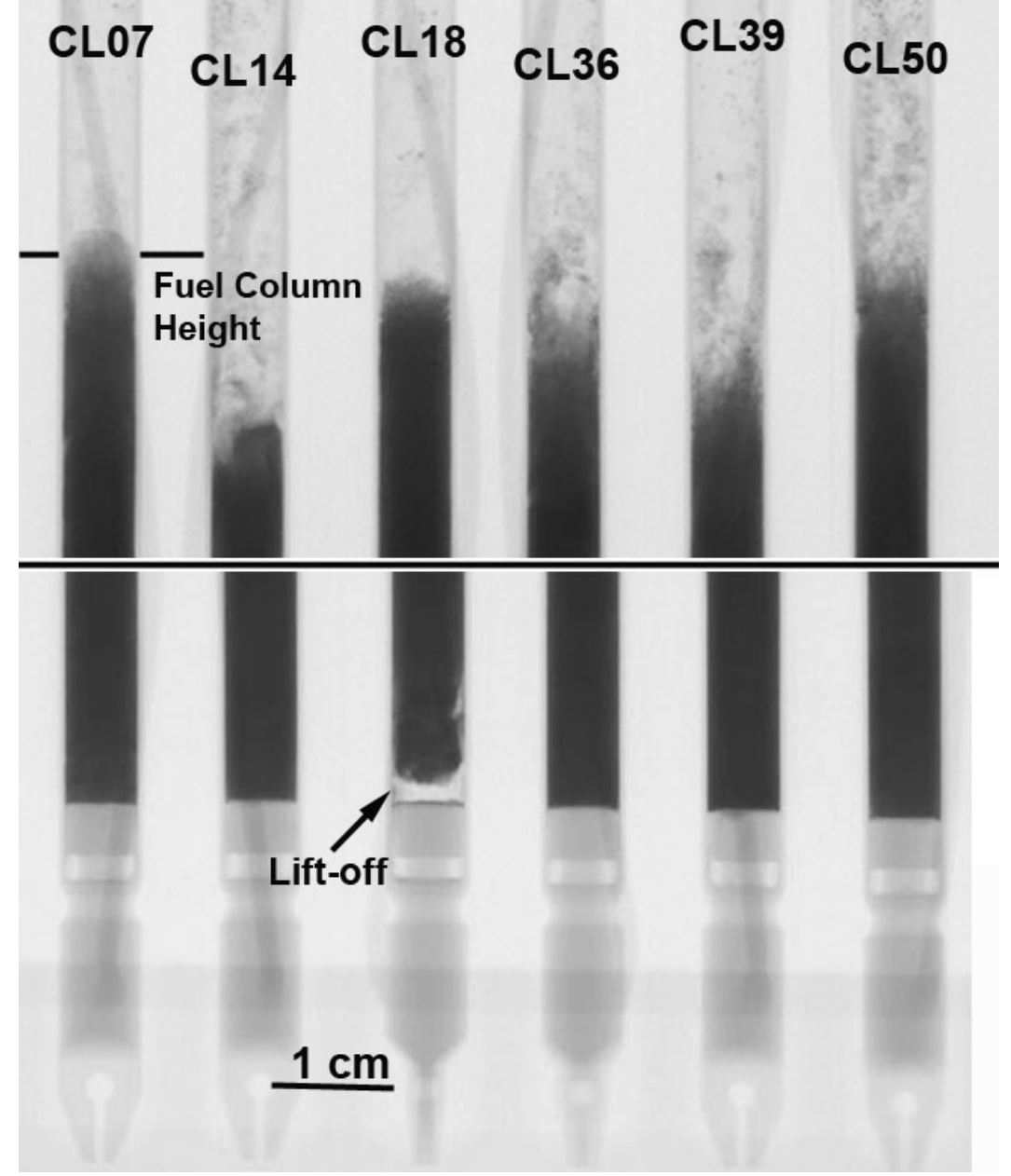

FIGURE 2 


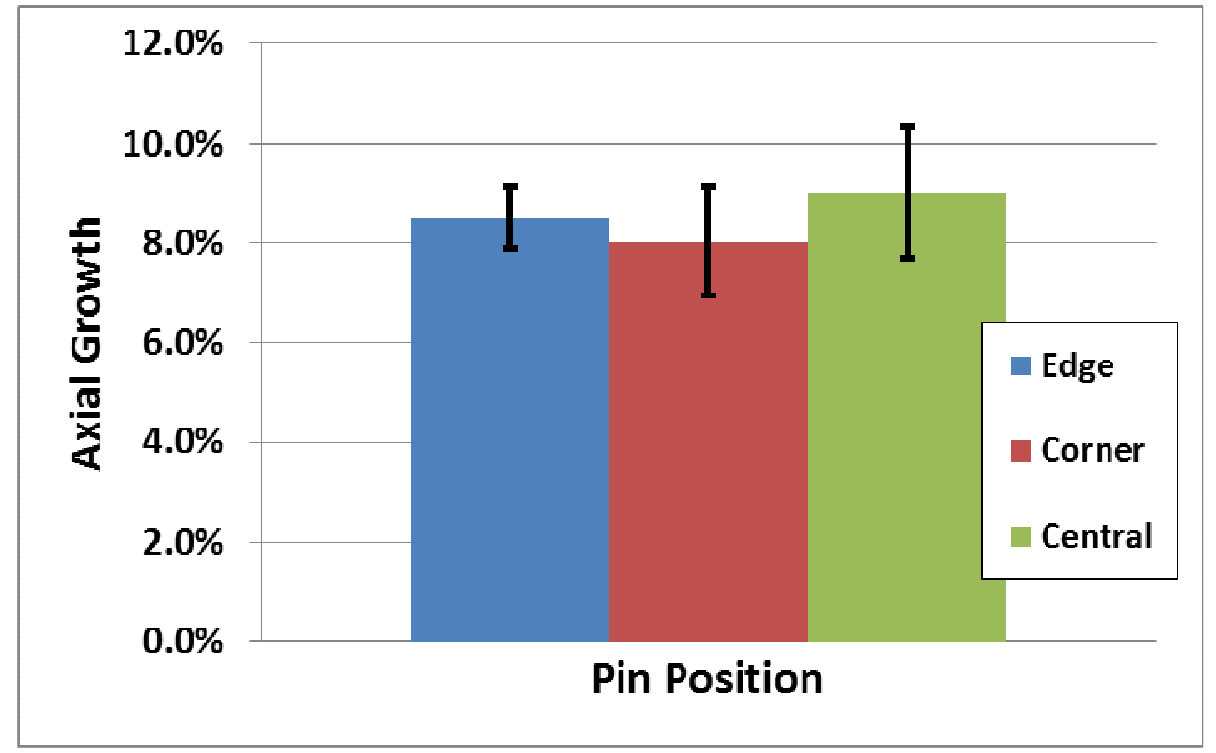

FIGURE 3

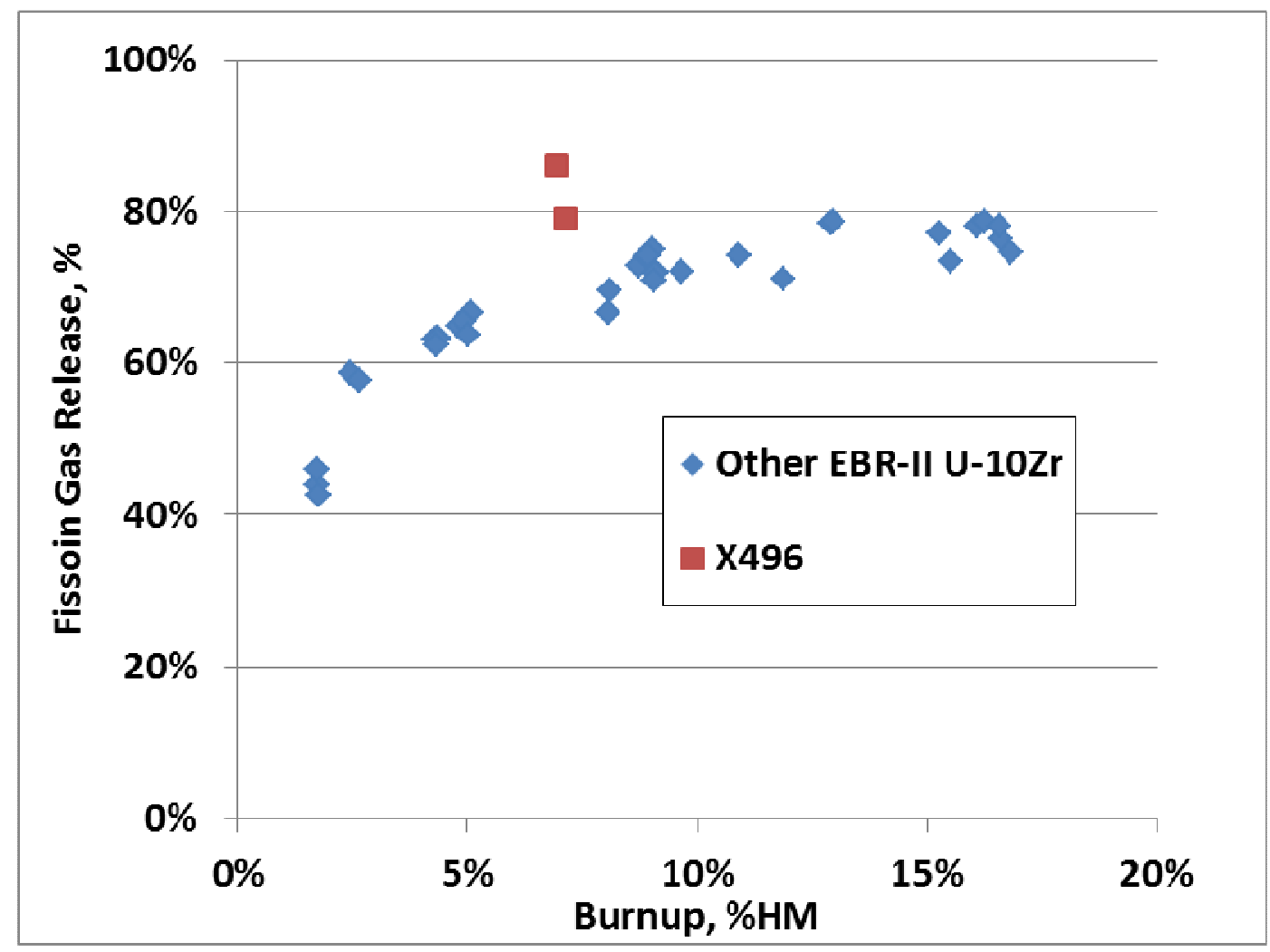

FIGURE 4 


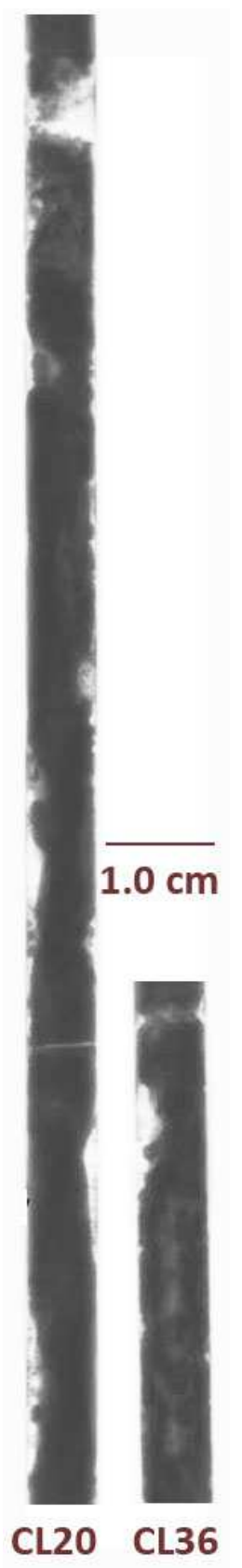

FIGURE 5 


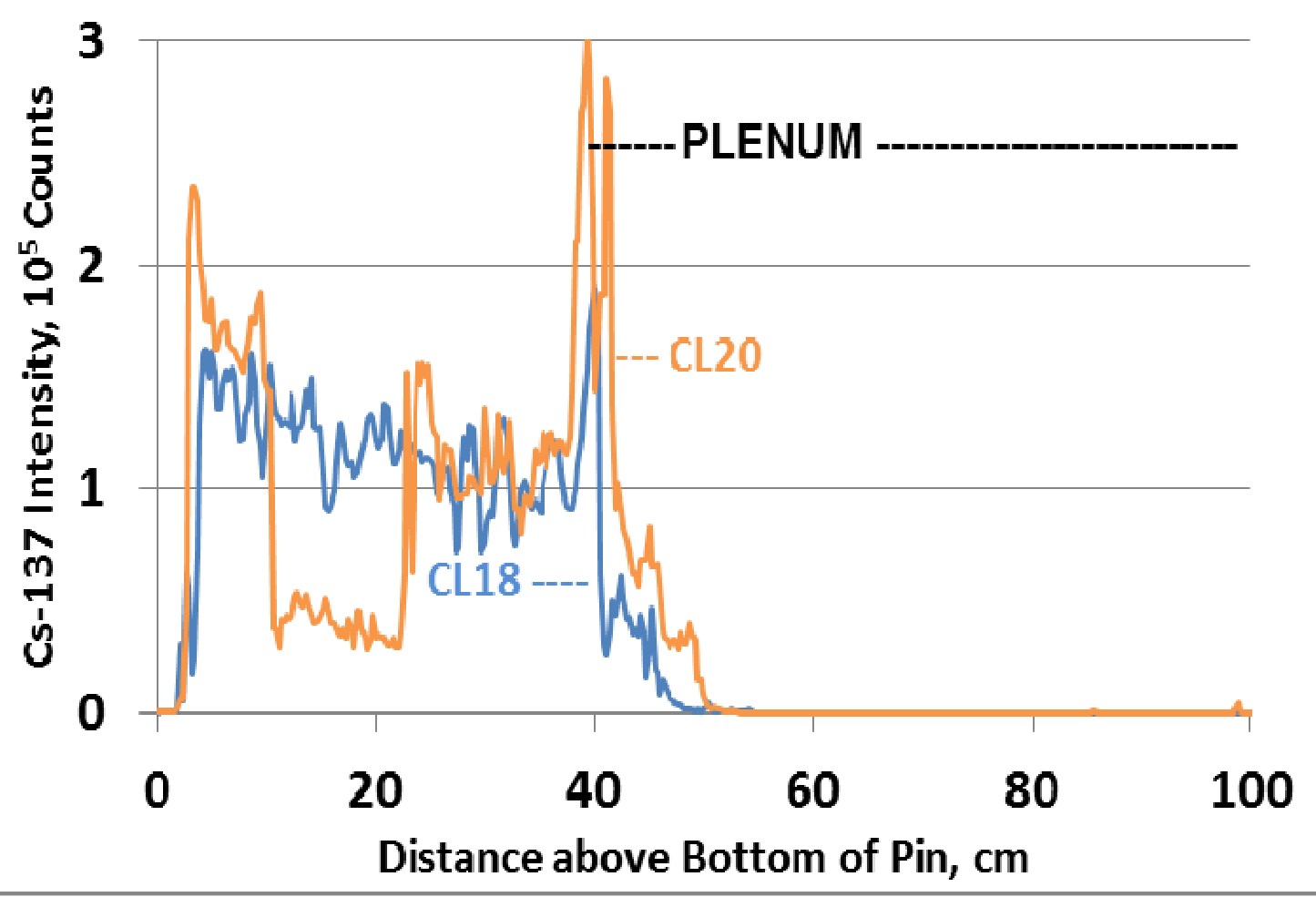

FIGURE 6 


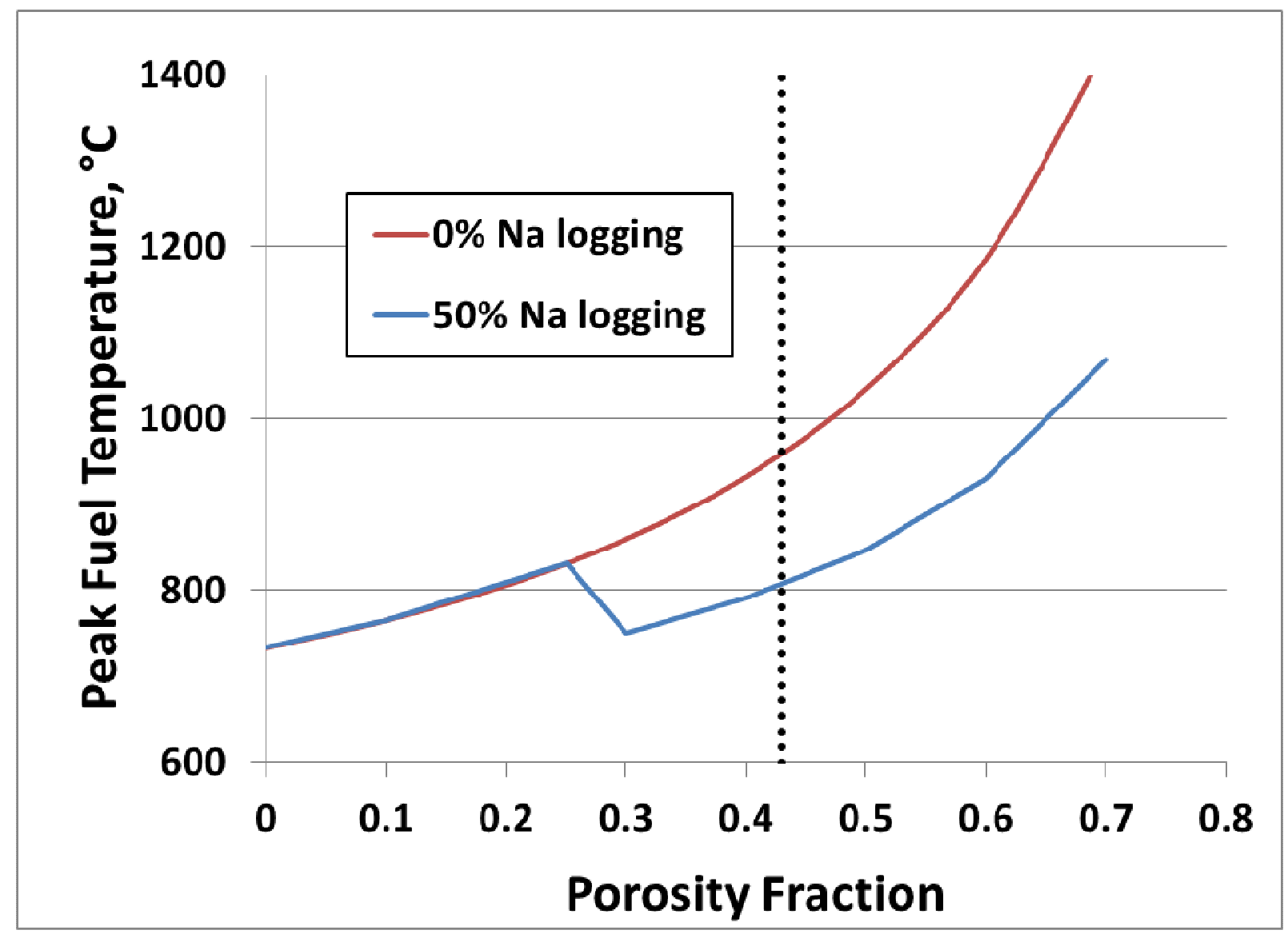

FIGURE 7 


\section{LIST of TABLES}

Table 1. Design parameters for X496 pins and assembly 6

Table 2 - Axial growth of fuel in X496 fuel pins as measured by analyzing neutron radiographs compared to peak thermal conditions. .8

TABLE 1

\begin{tabular}{|l|l|}
\hline Fuel Alloy, wt\% & $\mathrm{U}-10 \mathrm{Zr}$ \\
\hline Fuel Slug Diameter & $4.39 \mathrm{~mm}$ \\
\hline Fuel Slug Length & $34.3 \mathrm{~cm}$ \\
\hline Ratio of Plenum to Fuel Volume $\left(25^{\circ} \mathrm{C}\right)$ & 3.02 \\
\hline Plenum Volume $\left(25^{\circ} \mathrm{C}\right)$ & $15.7 \mathrm{~cm}^{3}$ \\
\hline Cladding Material & $\mathrm{HT9}$ \\
\hline Cladding Outer Diameter & $6.86 \mathrm{~mm}$ \\
\hline Cladding Wall Thickness & $0.56 \mathrm{~mm}$ \\
\hline Fuel Element Length & $101.1 \mathrm{~cm}$ \\
\hline Fuel Smeared Density (slug OD/cladding ID) & $58.6 \%$ \\
\hline Wire Wrap Diameter/Pitch & $1.85-\mathrm{mm} / 15.2-\mathrm{cm}$ \\
\hline Sodium Fill Above Fuel (25 $\left.{ }^{\circ} \mathrm{C}\right)$ & $0.64 \mathrm{~cm}$ \\
\hline Hex-duct Material & $316 \mathrm{SS}$ \\
\hline Maximum Element Linear Power & $63.3 \mathrm{~kW} / \mathrm{m}$ \\
\hline
\end{tabular}


TABLE 2

\begin{tabular}{|c|c|c|c|c|c|}
\hline $\begin{array}{c}\text { Grid } \\
\text { Location }\end{array}$ & Pin ID & $\begin{array}{c}\text { BOL Fuel } \\
\text { Centerline } \mathrm{T} \text {, } \\
{ }^{\circ} \mathrm{C}\end{array}$ & $\begin{array}{c}\text { BOL Inner } \\
\text { Cladding } \mathrm{T} \text {, } \\
{ }^{\circ} \mathrm{C}\end{array}$ & $\begin{array}{c}\text { Average Burnup, } \\
\text { at. } \% \mathrm{HM}\end{array}$ & $\begin{array}{c}\text { Axial } \\
\text { Growth, \% }\end{array}$ \\
\hline 1 & CL10 & 751 & 501 & 7.1 & $10.1 \%$ \\
\hline 2 & CL45 & 755 & 506 & 7.2 & $8.6 \%$ \\
\hline 3 & CL23 & 755 & 506 & 7.2 & $8.9 \%$ \\
\hline 4 & CL48 & 752 & 501 & 7.2 & $8.8 \%$ \\
\hline 5 & CL43 & 754 & 506 & 7.1 & $9.3 \%$ \\
\hline 6 & CLO2 & 766 & 521 & 7.1 & \\
\hline 7 & CL37 & 767 & 524 & 7.2 & \\
\hline 8 & CL46 & 764 & 521 & 7.2 & $9.2 \%$ \\
\hline 9 & CL25 & 756 & 508 & 7.2 & \\
\hline 10 & CL32 & 754 & 507 & 7.0 & $8.1 \%$ \\
\hline 11 & CL17 & 768 & 525 & 7.0 & \\
\hline 12 & CL13 & 771 & 532 & 7.1 & \\
\hline 13 & CL40 & 771 & 532 & 7.1 & \\
\hline 14 & CL16 & 767 & 526 & 7.2 & $9.5 \%$ \\
\hline 15 & CL44 & 757 & 509 & 7.2 & $8.9 \%$ \\
\hline 16 & CL28 & 751 & 501 & 6.9 & $7.3 \%$ \\
\hline 17 & CL38 & 767 & 523 & 7.0 & $8.9 \%$ \\
\hline 18 & CL39 & 771 & 533 & 7.0 & $8 \%$ \\
\hline 19 & CL20 & 772 & 536 & 7.1 & $7 \%$ \\
\hline 20 & CL29 & 771 & 534 & 7.1 & $8 \%$ \\
\hline 21 & CL07 & 766 & 524 & 7.1 & $11 \%$ \\
\hline 22 & CL14 & 754 & 506 & 7.2 & $7 \%$ \\
\hline 23 & CL06 & 756 & 507 & 6.9 & $8.0 \%$ \\
\hline 24 & $\mathrm{CL21}$ & 769 & 528 & 7.0 & $7.6 \%$ \\
\hline 25 & CL50 & 772 & 534 & 7.0 & $11 \%$ \\
\hline 26 & CL36 & 772 & 535 & 7.0 & $9 \%$ \\
\hline 27 & CL42 & 768 & 529 & 7.1 & $9.8 \%$ \\
\hline 28 & CL11 & 757 & 511 & 7.1 & $8.1 \%$ \\
\hline 29 & CL08 & 756 & 508 & 6.9 & $9.1 \%$ \\
\hline 30 & CL18 & 768 & 526 & 6.9 & $10 \%$ \\
\hline 31 & CL47 & 769 & 529 & 7.0 & $10.0 \%$ \\
\hline 32 & CL30 & 768 & 527 & 7.0 & $7.1 \%$ \\
\hline 33 & CL31 & 757 & 511 & 7.0 & \\
\hline 34 & CL05 & 752 & 503 & 6.8 & $7.4 \%$ \\
\hline 35 & CL15 & 757 & 510 & 6.9 & $7.9 \%$ \\
\hline 36 & CL12 & 758 & 511 & 6.9 & $7.7 \%$ \\
\hline 37 & CL22 & 754 & 506 & 7.0 & $7.6 \%$ \\
\hline
\end{tabular}

*The fuel length is comprised of two half-length fuel slug; outer row shaded in blue, $\square$ edge of bundle, red, $\square$ corner of bundle 